\title{
7 \\ Bump up the Energy: \\ Engaging Students in Online Forums
}

\author{
Betty Cunnin, Alice Macpherson, \& James Alan Matteoni \\ Kwantlen Polytechnic University
}

Educators know that to engage learners in the enterprise of critical thinking, learner's need to care enough to pay attention, and feel safe enough to take intellectual risks. When interacting asynchronously in online forums, it can become even more challenging to create a space that encourages reflective, integrative, and higher order thinking. In this paper, we present four strategies we found effective to connect university horticulture students to the course content and to each other in online forums. By building relationships to foster a social presence, making certain the topics for discussion are temporal and connected to students lives, have meaning both in content and course value, and by providing students some choice about what conservations they engage in, instructors can support students to create meaningful dialogical conversations that surpass the shallow fact finding exchanges that online learner's habitually engage in.

\section{Introduction}

$\mathrm{W}$ e believe that to think deeply, learners need connections. To foster students' connection to each other and deepen their thinking we used online discussion forums incorporating "less case-studies, less structure, and more opiniontype work" (student post, 2010). As horticulture instructors we are interested in exploring ways we can design online discussion forums to bump up the energy and get students' attention. We wanted our students to go beyond shallow, information-seeking exchanges. Our intent was to design learning tasks where students could genuinely and freely think and converse about matters of importance. We examined the ways students use these tools to create meaningful dialogical conversations so that the enigmatic exchanges, reconsideration, and testing of ideas needed in a landscape of continuous multiplicities could occur. The authors wanted to see how students facilitated transformative knowledge construction among their peers about the extant local and global policies and practices related to horticulture. 


\section{Online Forums}

The move to increase computer-mediated learning in universities, largely due to the administrative push and learner pull for distance learning, is backed by research that finds digital communication technologies can encourage conversations and connections, both formally as a structured online component of a course, and informally as a looselystructured online space for conversation (Rovai \& Barnum, 2003). In particular, asynchronous online discussion forums are purported to support the social construction of knowledge (Cheung, Hew, \& Ng, 2008; Schrire, 2006).

Students learn and build knowledge when they can contribute and engage in meaningful ways. Literature searches regarding "asynchronous online forums" reveal students will often choose to provide insubstantial fragmented information-seeking posts and fact-providing responses (Weigel, 2005). Wise, Padmanabhan, and Duffy (2009) caution that an "information-only focus results in a situation where even though participants are 'together' in an online space, their attention or 'learning focus' is entirely centered on their external situation" (p. 17). Yet despite increasing demand for access to digitally delivered, 'anywhere anytime' programs, many higher learning institutions, more importantly their instructors and students, lack access to 'high investment' digital tools with dynamic creative capacity for getting the learners attention (Gee, 2003). It follows then, that the capacity that online learning environments have to support the construction of knowledge depends largely on how the technology is implemented and used in learning (Schrire, 2006). Learners are less likely to engage with each other in the sense of negotiating and building meaningful knowledge. Instead, the forum becomes simply another, albeit more multifaceted, information resource to be consumed. That is, even though students can use the forums well enough to get good grades and acceptably answer the questions, what are they really learning?

The learning management systems (LMS) used for delivery, Weigel (2005) cautions, must not be considered to be self-implementing technologies. He warns the structural constraints of low investment LMS potentially "canalizes our collective creativity by forcing e-learning technologies into the familiar classroom categories of lectures, discussions, and exams" (p. 55). Because learning forums can be quite restrictive in terms of user control or dynamic creativity, we knew we had to somehow up the ante to get students to engage beyond a transmission level and towards a transactional level (Mezirow, 2000). This meant having learners take risks and provide considered and collegial responses, as opposed to bureaucratic or pedantic replies. Our goal was to create a space where that could happen.

The forums, where students were assigned partially structured learning tasks where they were explicitly asked to provide opinions and reflections on current topical issues related to the course work (see Figure 1), could be seen to undertake a Vytgotskian, peer-to-peer route of knowledge-building.

In the Botany course, students could selfselect one or more of the three instructor-initiated forums. In the Horticulture Apprenticeship course, students were asked to create a thread with their

\begin{tabular}{|l|l|l|}
\hline \multicolumn{1}{|c|}{ Courses } & \multicolumn{1}{|c|}{ Forum Topics } & \multicolumn{1}{c|}{ Participation } \\
\hline Botany & $\begin{array}{l}\text { Genetically Modified Organisms- } \\
\text { Franken Foods, Biodiversity, } \\
\text { Global Warming }\end{array}$ & $\begin{array}{l}\text { Choose any of the three forums, } \\
\text { bounce around }\end{array}$ \\
\hline Horticulture Apprenticeship & $\begin{array}{l}\text { Local Municipal Tree Preservation } \\
\text { Bylaws }\end{array}$ & $\begin{array}{l}\text { Post summary report for one } \\
\text { municipality, and reply (minimum) } \\
\text { to any other two threads }\end{array}$ \\
\hline
\end{tabular}

FIGURE 1

The Forums 
findings and personal observations or opinions from a paper they had written on a self-selected local municipal tree preservations bylaw. They were also required to reply and comment on no less than two other threaded discussions from another student.

\section{Instructional Design}

Transformative learning is dependent on a number of design principles, including that it needs to be sustained overtime. Transformative learning is a process whereby learners "elaborate, create, and transform their meaning schemes (beliefs, feelings, interpretations, decisions) through reflection on their content, the process by which they were learned, and their premises (social context, history, and consequences)" (Mezirow, 2000, p. 16).

Mezirow's (2000) criteria for transformative learning, and similarly Garrison's Practical Inquiry Model (Garrison \& Archer, 2000) for online learning, provide a model for coding the data. Each describes a learning process of "becoming critically aware of one's own tacit assumptions and expectations and those of others and assessing their relevance for making an interpretation" (Mezirow, 2000, p.4). Whereas Mezirow suggests the ability to elaborate, create, and transform knowledge into practice leads to transformative learning experiences, Garrision's model of critical inquiry is represented by four cognitive phases of triggering, exploring, integrating, and resolving.

In each forum, the instructor's participation was non-directive, providing initial welcoming, and acting as distant observer of the exchanges mostly to ensure collegial and expected contributions. The instructors were present to read and prompt the discussion. With their peers, students were expected to co-generate knowledge as it pertained to their studies in the courses. To avoid replicating the "uncritical acceptance of the traditional features of the classroom model," we provided "students with the experience of creating knowledge assets that others will find useful." This approach "provides a powerful impetus for study and research" by "encourag[ing] the development of important workplace skills (e.g., working collaboratively in virtual teams, providing critical yet tactful feedback, discerning the relevance of information)" (Weigel, 2005, p. 64). This peer interaction helped students practice new vocabulary and horticultural discourse. The ability to write and (re)read their own and each other's posts further allowed learners to grasp the meaning of new concepts and terminology and practice the art of persuasive argument (peripheral learning). An example of this social learning can be seen in the following conversation regarding genetically modified organisms (GMO's) and cancer risk:

Student 1: This topic is very scary. What is worse is that labels are not required in Canada indicating whether or not the food you are purchasing has been modified. I think that consumers should have the right to know if what they are eating has been genetically manipulated even if it is a small portion of something like a certain type of grain in bread. In my opinion, genetic engineering has not been around long enough for people to know whether or not it is truly safe in the long term. I for one do not feel like being an unwilling participant in this experiment.

Student 2: I agree that GMO foods should be marked so I know what we're eating, but at the same time, I don't believe they are all dangerous, and production should be stopped...I decided to research the database on genetically modified vegetables, and I came across an interesting study.

While no detailed demographic data was collected, horticulture students tend to range in age from low 20 s to late 30 s, and almost split $(60 \mathrm{M} / 40 \mathrm{~F})$ in terms of sex. While most had used a computer before, many report using them for recreation and information communication. When asked, regardless of being 
in the face-to-face or online section, most students found the Moodle forums easy to use (Figure 2).

\section{Discussion}

We found that partially structured forums with more opinion-type work fostered connections to each other and deepened their thinking. Horticulture students were most interested in participating in discussions when they felt a sense of community, where there were fewer tasks directed by the instructor, and where the forum topic provided an opportunity to post their questions and opinions to each other. One student commented:

It was really good to see what was happening in other municipalities. I wouldn't have known about the trees in North Van if T. wasn't so freaked about the lack of protection there.

\section{Themes}

Four themes regarding student engagement for transformative learning emerged from our experiences in these forums. If students are to explore, integrate, and test their knowledge, then building relationships, provocative topics, value to students, and providing student choice are supportive themes to be considered in the instructional design of online forums (Shrire, 2006).

\section{Building relationships}

It is best not to assume learners are 'digital natives' who will intuitively know how to use information communication technologies. Accordingly, our students were provided with basic information of netiquette and acceptable expectations for online communication in each course. As an online introduction to the learning community, students were asked to view the instructor's profile and post a picture of themselves and something they would feel comfortable sharing with their peers. They

\section{Moodle: "Easy to use."}

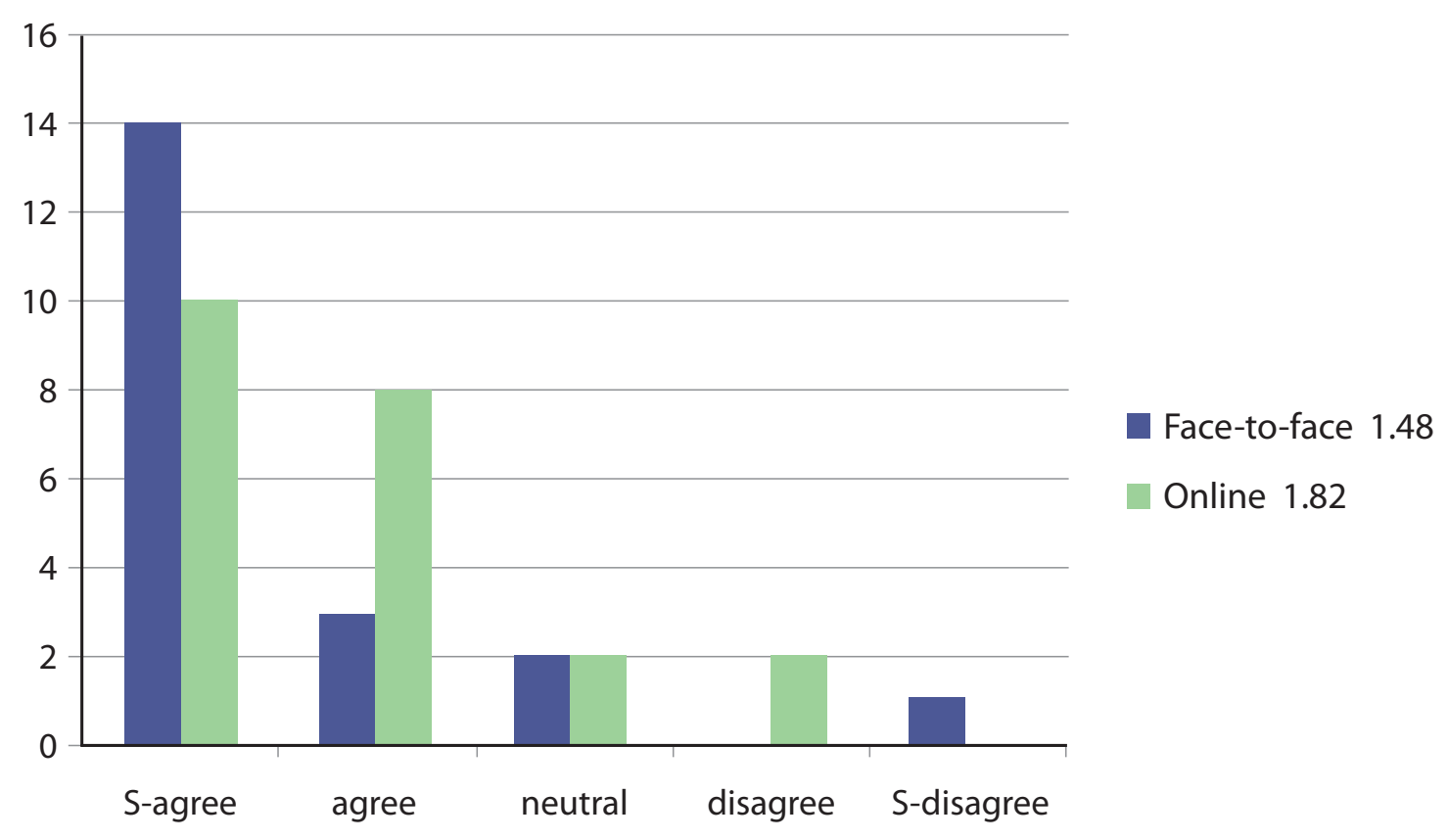

FIGURE 2

Moodle Ease of Use 
were encouraged in class and through prompts by the instructor to examine each other's profiles and, if relevant, link content about each person in their posts. This 'relational capital' plays an important role when the students are interacting with each other (Cheung et al., 2008). In some instances, it was the profile information that was the trigger for another's entrance into the discussion. In a discussion on the effects of fertilizer in the ocean, after glancing at the profiles of her peers, one student was triggered to ask a question about a peer who had an image of themselves scuba diving: "Have you seen evidence of the decline of the coral reefs in your diving?"

This thread brought others into the discussion either because of their own personal interests. Whether in face-to-face or online classes, students felt a sense of community develop through their interactive discussion in the forums (Figure 3).

Interaction between the learners themselves appears to be an important element regarding the effectiveness of the learning task. We saw numerous examples of relationship building where one learner is asking for and receiving a considered reply. Instructors need to be present, at least in the beginning and not directive in the conversation. Initially, instructors may need to demonstrate engagement, and trigger the conversation by asking open-ended questions or by providing some relevant personal information.

With regards to the instructor's referent power, learners will often wait for them to comment before replying. We found avoiding closed fact-based questions that one person can answer and rather asking open-ended questions that ask for opinions and ideas that do not have 'right' answers, was more likely to initiate a deeper conversation, promoting deep learning.

\section{Hot topics}

The second theme that emerged was that the topic needed to be sufficiently provocative to engage students. Being able to exchange their own ideas is essential to discourse in the field and in laboratory work. We found that the more contentious and current, or 'hotter,' the issue, the more likely students were to reflect and test their ideas with their peers.

\section{"I developed a sense of community through the forums."}

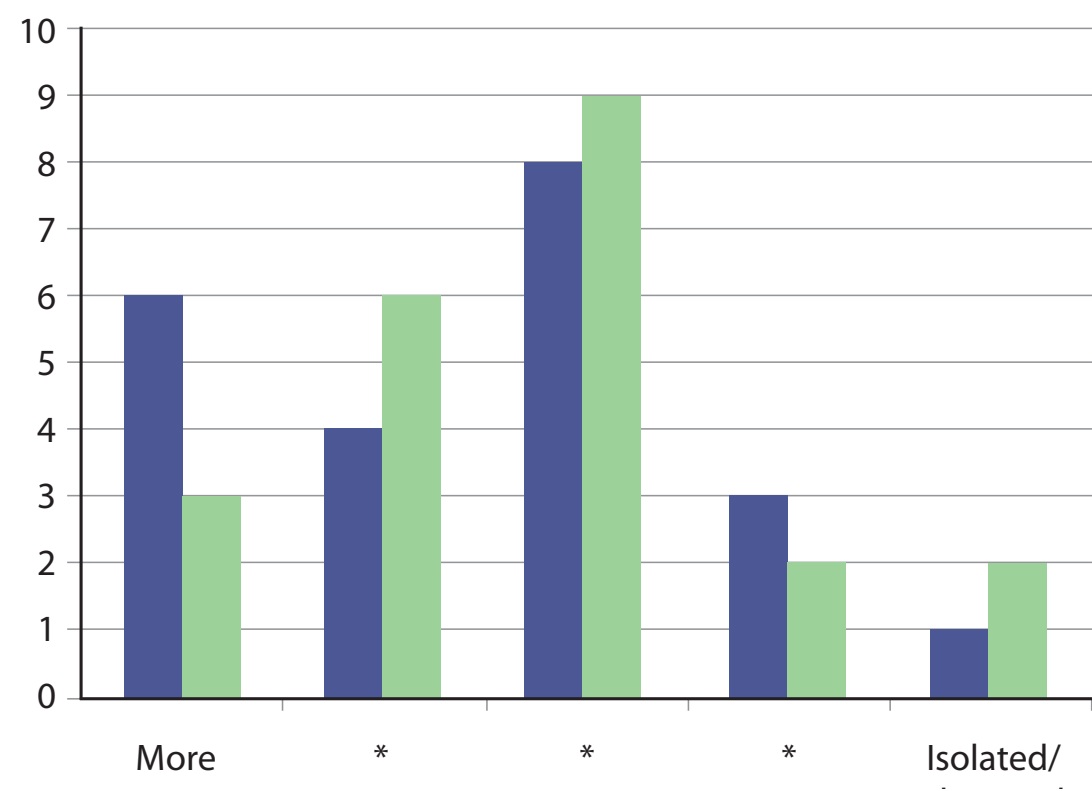

FIGURE 3

Sense of Community
Face-to-face 2.50

Online 2.90 
In addition to the forums being an integrated aspect of the curriculum and topical, in order to be able to explicitly reflect and consider ideas, learners need to have some prior knowledge about the topic. Cheung et al. (2008) found that "the lack of knowledge about a topic at hand is the most common reason cited by students (87\%) not to contribute in an online discussion" (p. 40). Students said that being able to quickly surf the Internet when they were reading or writing on a forum topic allowed them to explore and test their ideas more rigorously before submitting a post. Social learning could be seen in ongoing conversations online and in the classroom regarding the validity of Internet sources of information.

\section{Make it worth something}

Thirdly, there has to be value to the work the students do in the forums, both in terms of grades and relevance. Given the competition for their attention, it makes sense that unless learners are being rewarded with a grade, they will apply less effort in learning a task. Each of the forums had course grades assigned from 5-10\%. A grading scheme makes the expectations explicit and reduces learner anxiety.

In addition to being a hot topic, the students need to make a deeper, personal connection with the content. Cheung et al. (2008) found that students are more likely to contribute in forums "if they felt that the topics of ongoing discussion were interesting" beyond the curriculum (p. 40). Making connections between the course work and beyond provides a good opportunity for interdisciplinary thinking. This encourages students to make linkages to other courses, things they previously knew or heard about before. Some of the forum students asked that the forums stay open beyond the course end date so that they can continue the discussions. They also asked for more instructors across their discipline to be able to participate.

An example of the value of the forum beyond the classroom occurred when a group of students engaged in a discussion regarding a province wide pesticide ban. After some of the students went to a turf conference where there was a panel with West Coast Turf Association and the Suzuki Foundation, students made 147 posts over a weekend. When the instructor checked the forums he was amazed to see this learnerinitiated and voluntary thread generated so much discussion about the horticultural, recreational, social, and political manifestations of British Columbia implementing a cosmetic pesticide ban.

\section{Give students a choice}

Finally, the eagerness for students to contribute to the forums appears linked to their ability to make a choice regarding the threads and content of the posts they write and read. Students need to feel they can make choices as to when and where they join in, and the content of their comment. By increasing their options a few benefits arose. First, students generally reviewed more forums than they posted to. In the Botany course students looked at as many as five times more forums than they participated in. This extra reading gave students exposure to many more ideas than would occur in a conversation in the classroom. Additionally, asking students to provide their opinions, rather than a closed or prescribed answer, prompted them to reflect on their beliefs and consider how these beliefs informed their practices.

\section{Lessons Learned}

Transformative learning requires reflection that leads to a change in practice (Mezirow, 2000). As horticulture instructors, we want to grow our scholarship of teaching for higher learning in our domains of creating and managing plant ecologies in indoor and outdoor spaces. Upon reflection of our online forums, we saw great value in some of the approaches used that initially our students and us took for granted. Changes we intend to implement include:

- Provide students with early formative feedback.

- Increase the grade value of the forums.

- Ask students to reflect on instances and provide evidence from their posts where their contributions contributed to the growth of their own or their peers' knowledge. 
- Bring more of the forum discussion back into the classroom (in face-to-face classes).

- Celebrate learning communities.

\section{Conclusions}

Shallow exchanges of information do not engage members into discussion and dialogue with others in an online forum. Our analysis supports the idea that people are more engaged in conversation when they know something about one another, when the discussion occurs at a level that relates to their personal context, has broader use and exchange value, and when participants are given a choice to participate. Online forums may well be a part of an instructional approach to supporting our students to think in ways that they might be able to find solutions to today's 'wicked problems' (Conklin, 2005).

The significant variety among online course designs makes it difficult to characterize a typically successful online forum. One might just as well try to characterize a typical bug or plant. What works in one location or situation might not work in another. We examined the structure and process of the online forums and tasks, as well as the students' use and comments, to gain insight into the kinds and types of discussions students will choose to engage in along with four strategies that we identified to bump up the energy to engage students in transformative learning.

We invite you to join in this conversation and try things out: http://onlinelearning.kwantlen. $\mathrm{ca} /$ course/view.php?id=541. The enrolment key: blueberry.

\section{References}

Cheung, W., Hew, K., \& Ng, C. (2008). Toward an understanding of why students contribute in asynchronous online discussions. Journal of Educational Computing, 38, 29-50.

Conklin, J. (2005). Dialogue mapping: Building shared understanding of wicked problems. Wiley.
Garrison, D.R. \& Archer, W. (2000). A transactional perspective on teaching-learning: A framework for adult and higher education. Oxford, UK: Pergamon.

Gee, J. (2003). What video games have to teach us about learning and literacy? Computers in Entertainment, 1, 1.

Halpern, D. (1996). Thought and knowledge: An introduction to critical thinking (3rd ed.). Mahwah, New Jersey: Erlbaum.

Mezirow, J. (2000). Learning as transformation: Critical perspectives on a theory in progress. San Francisco, CA, USA: Jossey Bass.

Rovai, A. \& Barnum, K. (2003). Online course effectiveness: An analysis of student interactions and perceptions of learning. Journal of Distance Education, 18, 57-73.

Schrire, S. (2006). Knowledge building in asynchronous discussion groups: Going beyond quantitative knowledge. Computers and Education, 46, 49-70.

Weigel, V. (2005) From course management to curricular capabilities: A capabilities approach for the next generation. EDUCAUSE Review, 40(3), 54-67.

Wise, A., Padmanabhan, P., \& Duffy, T. (2009). Computer support for collaborative learning. Proceedings of the 9th international conference on Computer Supported Collaborative Learning, Rhodes, Greece (Vol. 2), 135-137.

\section{Biographies}

Betty Cunnin teaches landscape horticulture at Kwantlen Polytechnic University. Her interests include promoting the environmental, economic and social benefits of sustaining an urban forest. She can 
be reached at Betty.Cunnin@kwantlen.ca.

Alice Macpherson is the PD Coordinator for the Centre for Academic Growth at Kwantlen Polytechnic University, and works with other faculty members to support student engagement and learning in a variety of learning environments. She can be reached at Alice.Macpherson@kwantlen.ca.

James Alan Matteoni is an instructor in botany and pests at Kwantlen Polytechnic University's School of Horticulture. When not teaching, Jim can be found in the garden or on the slopes snowshoeing. He can be reached at Jim.Matteoni@kwantlen.ca. 